\title{
$\stackrel{\infty}{\circ}$ MERENJE PRELAZNIH OPTEREĆENJA NA DVA MODELA U AEROTUNELU T-38
}

\author{
Aleksandar Vitić, dipl. inž. \\ mr Marija Samardžić, dipl. inž. \\ Vojnotehnički institut
}

Rezime:

Pri ispitivanju modela $u$ „rafalnom" aerotunelu sa prekidnim dejstvom T-38, na Mahovim brojevima većim od 2, moraju se uzeti u obzir prelazne pojave koje se javljaju na početku i na kraju rada aerotunela. To su stanja kada su model $i$ aerovaga izloženi velikim aerodinamičkim silama i momentima. Ova kombinovana opterećenja mogu oštetiti modele $i$ aerovage, pa bi bilo potrebno unapred znati kolike se vrednosti očekuju za pojedine konfiguracije modela, kako bi se izvršio pravilan izbor aerovage $i$ odgovarajućih materijala za izradu modela. U tu svrhu postoje dijagrami koji pružaju mogućnost procene ovih opterećenja. Dijagrami su dobijeni na osnovu ispitivanja nekoliko različitih modela na Mahovim brojevima većim od 2.

$U$ radu su prikazana merenja prelaznih opterećenja na još dva modela, a rezultati su upoređeni sa već postojećim dijagramima.

Ključne reči: rafalni aerotunel, prelazna opterećenja, aerotunelski modeli, aerovage, šliren sistem.

\section{MEASUREMENT OF TRANSIENT LOADS ON TWO MODELS}

\section{Summary:}

The T-38 wind tunnel is a blowdown, intermittent-run type of wind tunnels. During model testing in the this type of wind tunnels, at Mach numbers higher than 2, transient loads which appear during the starting and stopping of the wind tunnel runs must be taken into consideration. These are the conditions when a model and the wind tunnel balance are exposed to large aerodynamic forces and moments. These combined loads can damage models and wind tunnel balances, and, for this reason, it is very important to determine them in advance for any particular model configuration so that an appropriate wind tunnel balance and materials for model manufacturing can be chosen. For that purpose there are graphs which give possibilities to estimate these loads. The graphs are based on experiments with a number of different models at Mach numbers higher than 2.

This paper gives the measurements of transient loads on two more models and the results are compared with the already existing graphs.

Key words: blowdown wind tunnel, transient loads, wind tunnel models, wind tunnel balances, Schlieren system. 


\section{Uvod}

Jtoku primopredajnih ispitivanja u aerotunelu T-38 Vojnotehničkog instituta u Beogradu uočene su izvesne pojave koje se javljaju pri startu i zaustavljanju rada aerotunela na Mahovim brojevima većim od $M=2$. Te pojave nazvane su ,prelazna stanja“ u kojima se aerodinamičke sile i momenti znatno povećavaju u odnosu na kasnije vrednosti pri stacionarnim režimima strujanja. Ova stanja izazvana su pojavom normalnog udarnog talasa koji se iz „grla“ mlaznika premešta iza modela i koji, nažalost, nije normalan na osu modela već zaklapa izvestan ugao. To je razlog što dolazi do razlike u pritiscima na gornjaci i donjaci modela koja generiše sile i momente, a oni snažno pomeraju model iz njegove početne pozicije. Ova kombinovana opterećenja javljaju se i u ravni propinjanja i u ravni skretanja i toliko su velika da se moraju ozbiljno uzeti u obzir pri dizajniranju modela i izbora aerovage.

$U$ radu su prikazani rezultati merenja prelaznih opterećenja na dva različita modela u aerotunelu T-38 na brzinama većim od $M=2$. Dobijeni rezultati upoređeni su sa rezultatima dobijenim u ranijim ispitivanjima prelaznih opterećenja sa drugim modelima [1-4].

\section{Eksperiment}

\section{Opis modela i aerovaga}

$\mathrm{U}$ eksperimentu su korišćena dva modela: Model 1 iz test-programa GE2000 [5] i Model 2 iz test-programa GRAN40 [6].

Model 1 bio je montiran na aerovagu VTI40B i preko stinga prečnika $40 \mathrm{~mm}$ vezan za sistem koji služi za promenu napadnog ugla. Na slici 1 prikazana je skica ovog modela, a na slici 2 slika modela u radnom delu aerotunela T-38. Model je cilindričnog oblika sa oživalnim vrhom. Dužina modela je $700 \mathrm{~mm}$, a prečnik $65 \mathrm{~mm}$. Na kraju modela nalaze se pravougaona ili olučasta krila. Ispitivano je nekoliko različitih konfiguracija ovih krila.

\section{SI. 1 - Skica Modela 1 iz test-programa GE2000}

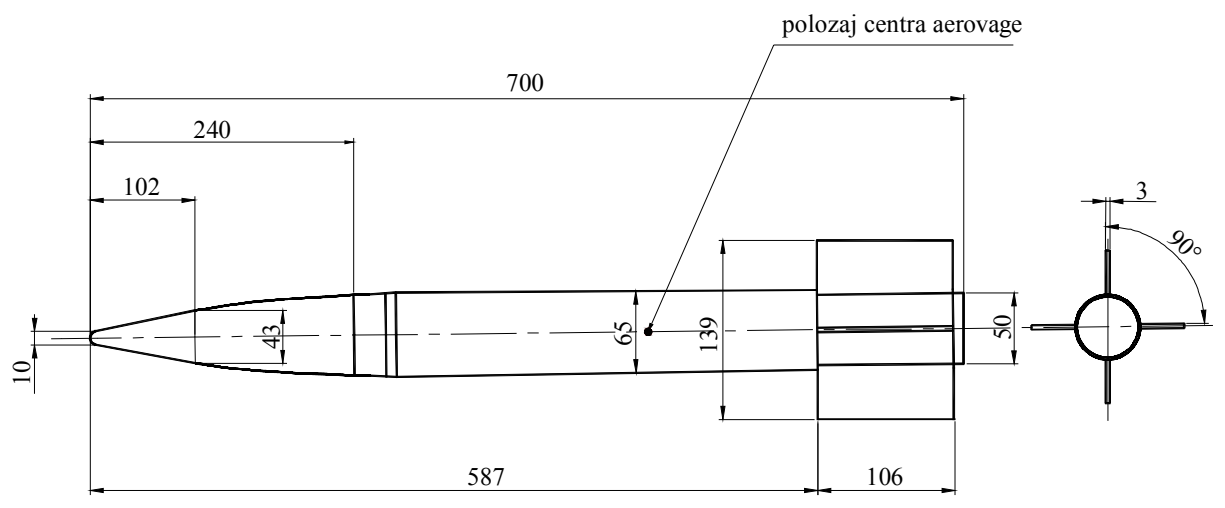




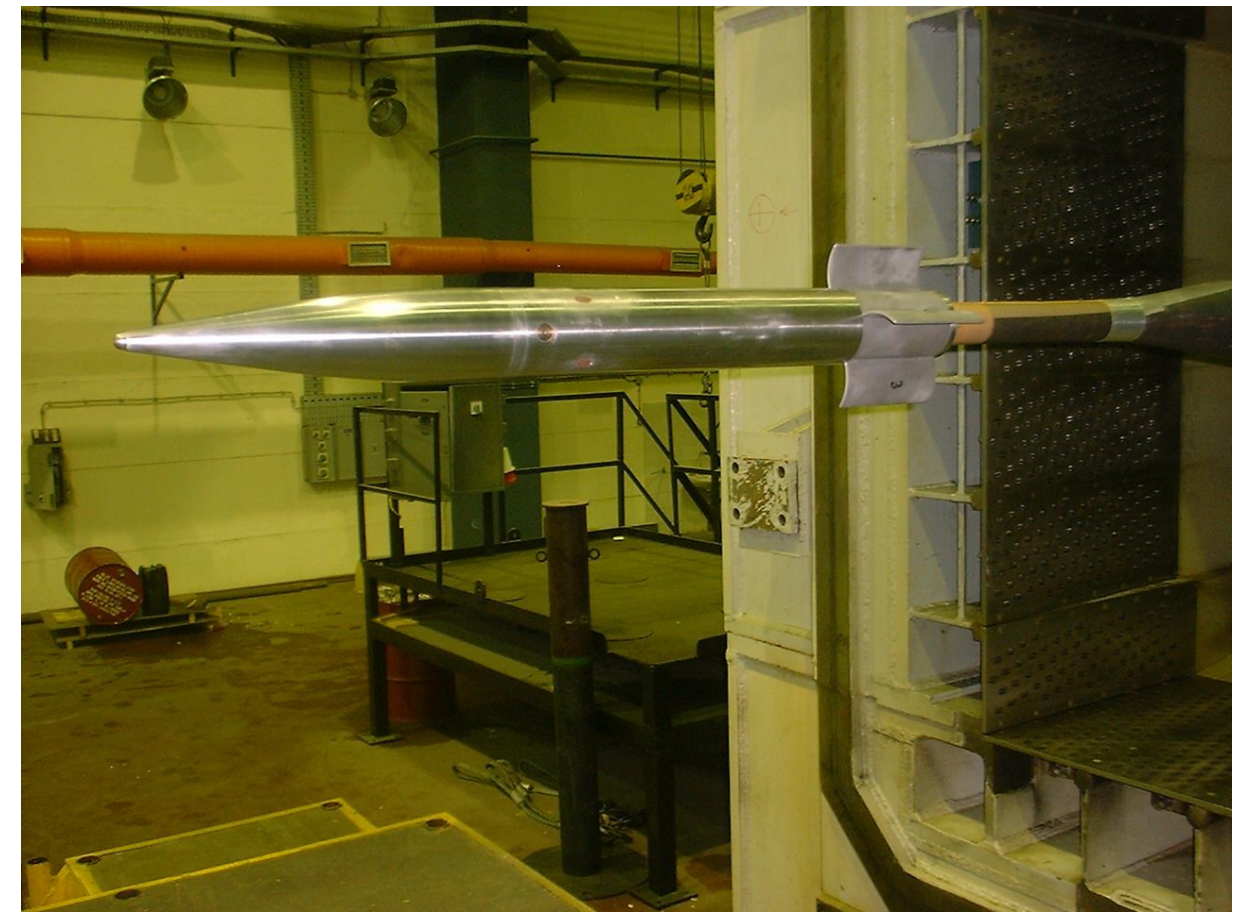

SI. 2 - Model 1 sa olučastim krilima u radnom delu aerotunela T-38

Model 2 bio je montiran na aerovagu ABLE 1" MK XXIIIA i preko stinga prečnika $32 \mathrm{~mm}$ vezan za sistem koji služi za promenu napadnog ugla. Skica modela sa osnovnim dimenzijama prikazana je na slici 3. Model je cilindričnog oblika sa oživalnim vrhom. Dužina modela je $206,8 \mathrm{~mm}$, a prečnik $39,8 \mathrm{~mm}$. Položaj centra aerovage smešten je na $134,91 \mathrm{~mm}$ od vrha modela.

SI. 3 - Skica Modela 2 iz test-programa GRAN40

206,8

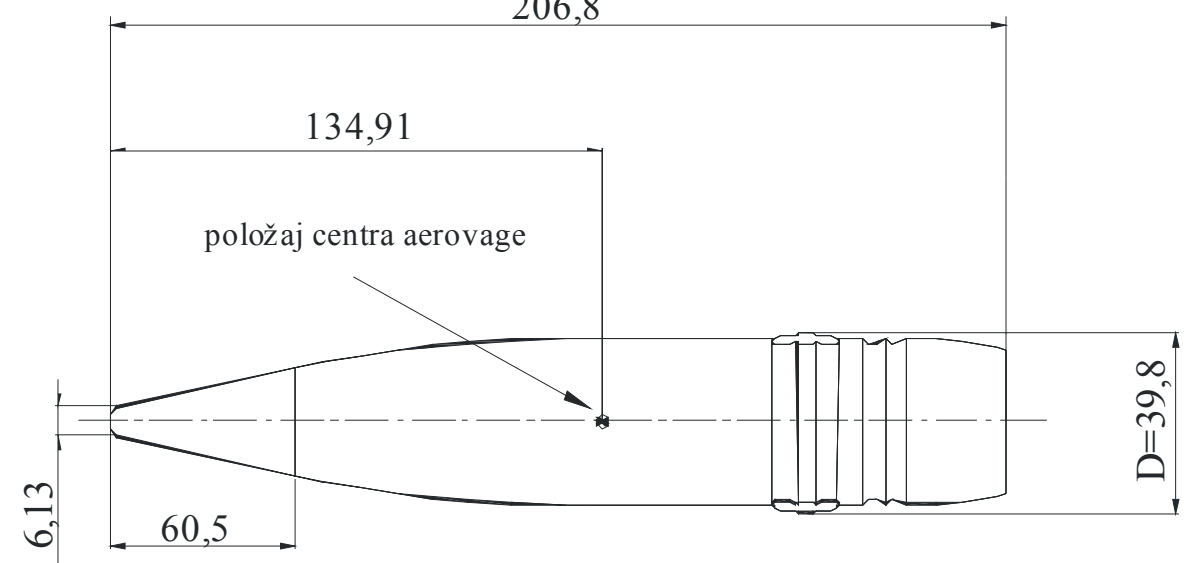




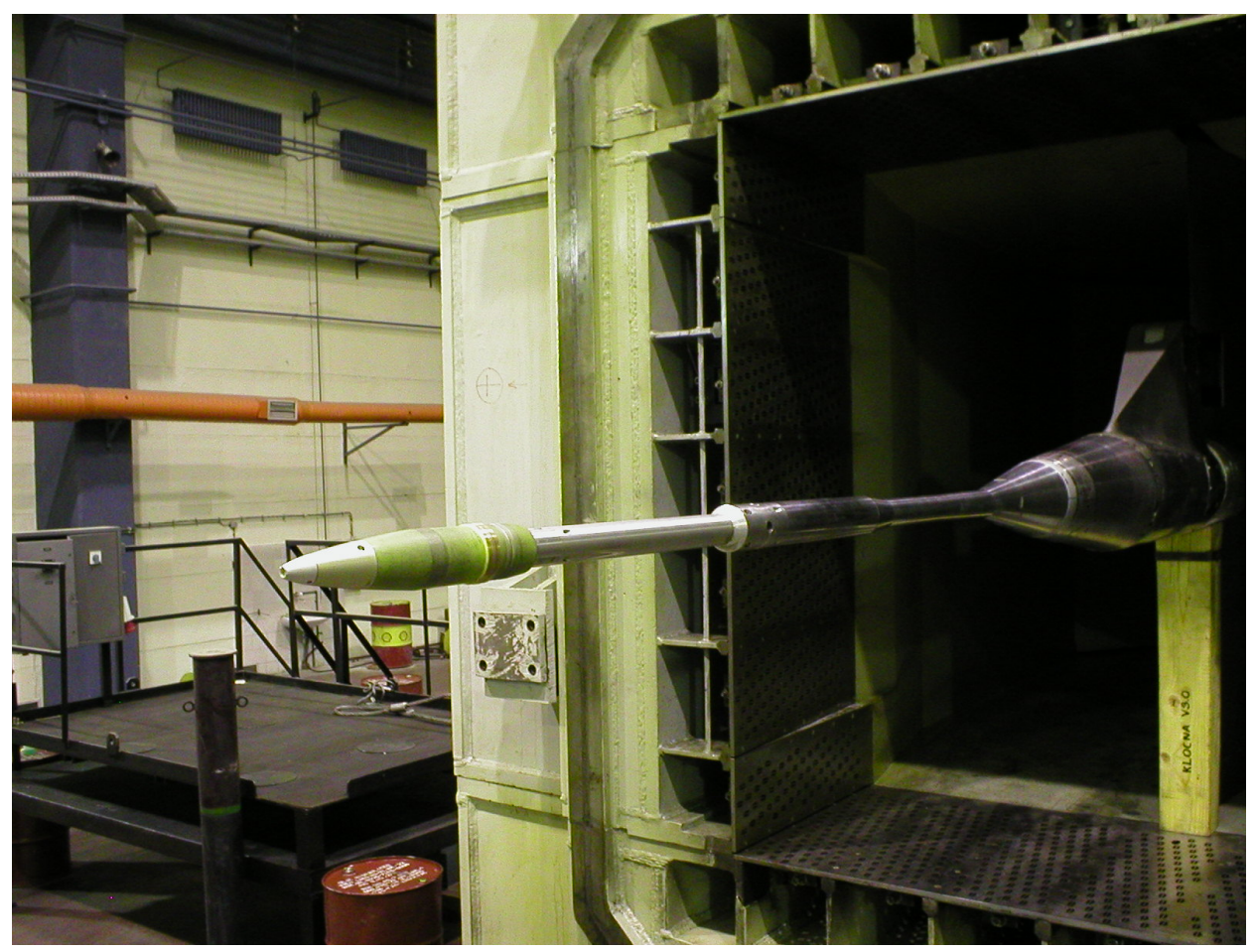

SI. 4 - Model 2 u radnom delu aerotunela T-38

Opis aerotunela T-38

Aerotunel $T-38$ u VTI-u je prekidnog dejstva sa natpritiskom i radnim delom kvadratnog poprečnog preseka dimenzija 1,5 m x 1,5 m [7]. Opseg Mahovih brojeva koji se može postići u radnom delu je od 0,2 do 4,0 sa maksimalnim Rejnoldsovim brojem do 115 miliona po metru. Regulacija i održavanje Mahovog broja je $\pm 0,3 \%$ od zadate nominalne vrednosti. Zaustavni pritisak u radnom delu može biti održavan između 1,1 bar i 15 bara, što zavisi od Mahovog broja, dok je tačnost regulacije $\pm 0,3 \%$ nominalne vrednosti. Dužina trajanja jednog ispitivanja (jednog "rafala") iznosi od $6 \mathrm{~s}$ do $60 \mathrm{~s}$ i zavisi od Mahovog broja i pritiska duvanja.

\section{Instrumentacija i prikupljanje podataka}

Potrebni pritisci mere se apsolutnim i diferencijalnim davačima tipa Mensor i Druck različitog opsega. Nelinearnost i histerezis ovih davača je oko $0,02 \%$ punog opsega. 
Precizni davači pozicije, tzv. rizolveri, montirani su u mehanizam za promenu napadnog ugla i ugla valjanja. Tačnost sistema za očitavanje napadnog ugla je $\pm 0,05^{\circ}$, a za ugao valjanja $\pm 0,25^{\circ}$. Za merenje aerodinamičkih sila i momenata na Modelu 1 korišćena je šestokomponentna aerovaga $V T I 40 B$, koja je montirana na sting prečnika 40 $\mathrm{mm}$. Njena tačnost je $0,25 \%$ punog opsega. Aerovaga je baždarena pre ovog ispitivanja. Za merenje aerodinamičkih sila i momenata na Modelu 2 korišćena je šestokomponentna aerovaga ABLE 1" MKXXIIIA, montirana na sting prečnika $32 \mathrm{~mm}$, čija tačnost iznosi $0,3 \%$ punog opsega. Aerovaga je, takođe, baždarena pre testa. Sistem za prikupljanje podataka sastoji se od 64-kanalnog sistema tipa Teledyne pod kontrolom računara $P C$ Compaq. Na svim analognim kanalima izabrano je odgovarujuće pojačanje i postavljeni su filteri odgovarajuće granične učestanosti. Podaci sa svih analognih kanala se digitalizuju $A / D$ konvertorom rezolucije 16 bita. Svi kanali su očitavani istom brzinom od 400 podataka u sekundi.

Digitalizovani podaci primaju se na računar Compaq Alpha Server DS20E i zapisuju na disk za kasniju obradu.

\section{Vizualizacija strujanja}

Vizualizacija strujanja obavljena je sistemom Šliren, a slike su prikupljene na PC računaru koji se nalazi u kontrolnom centru aerotunela [8]. Sistem je takozvanog tipa $Z$ sa paralelnim snopom svetlosti prečnika $900 \mathrm{~mm}$. U svetlosnom kabinetu nalazi se ksenon lampa sa procepom i dva ravna ogledala, koji služe da usmere snop svetlosti na pr-

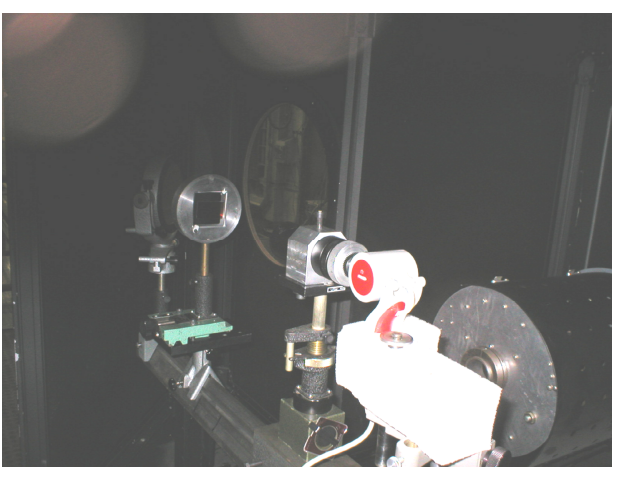

SI. 5 - Minijaturna Web kamera u prijemnom kabinetu sistema Šliren vo kolimatorsko ogledalo žižne daljine $7200 \mathrm{~mm}$. Na drugoj strani aerotunela nalazi se veliko ravno skretno ogledalo prečnika 1300 $\mathrm{mm}$ i drugo kolimatorsko ogledalo iste žižne daljine kao i prvo. U prijemnom delu sistema nalaze se malo ravno ogledalo, filter $u$ boji, mali teleskop za suženje snopa svetlosti i minijaturna Web kamera. Na slici 5 prikazana je Web kamera u prijemnom kabinetu sistema Šliren koji je instaliran $\mathrm{u}$ hali aerotunela T-38. 


\section{Obrada rezultata merenja Obrada rezultata merenja u stacionarnom režimu strujanja}

Obrada podataka u stacionarnom režimu strujanja vrši se posle svakog „rafala“, pri čemu se koristi standardni softverski paket T38APS za obradu merenja u aerotunelima VTI. Obrada se izvodi u nekoliko faza:

- čitanje zabeleženih sirovih podataka, normalizacija i prevođenje u standardni format;

- određivanje parametara strujanja, tj. primarni merni sistem;

- određivanje položaja modela;

- određivanje aerodinamičkih koeficijenata u stacionarnom režimu strujanja.

Svaka faza obrade izvodi se posebnim softverskim modulom.

\section{Obrada rezultata merenja aerodinamičkih sila i momenata u prelaznom režimu}

Obrada podataka u prelaznom režimu strujanja izvršena je na kraju celokupnog predviđenog test-programa. Na osnovu zabeleženih „sirovih“ podataka izrađeni su dijagrami, prikazani u primerima na slikama 6 i 7 , gde se vide vrednosti sila i momenata u prelaznom, kao i u stacionarnom režimu strujanja izmereni aerovagom. Za svaki pojedinačni „rafal“, za oba modela, pročitane su vrednosti sila i momenata, a zatim su, korišćenjem jednačine 1-6, izračunati normalizovani koeficijenti. Svi podaci zapisani su u tabelama 1 i 2.

$$
\begin{aligned}
& \left.\left.\left.k_{x}=\frac{F X X}{S_{x}} \ldots . .1\right) \quad k_{y}=\frac{F Y Y}{S_{Y}} \ldots . .2\right) \quad k_{z}=\frac{F Z Z}{S_{Z}} \ldots . .3\right) \\
& \left.\left.\left.k_{l}=\frac{M X X}{B S_{Z}} \ldots . .4\right) \quad k_{m}=\frac{M Y Y}{L S_{Y}} \ldots . .5\right) \quad k_{n}=\frac{M Z Z}{L S_{Z}} \ldots . .6\right)
\end{aligned}
$$




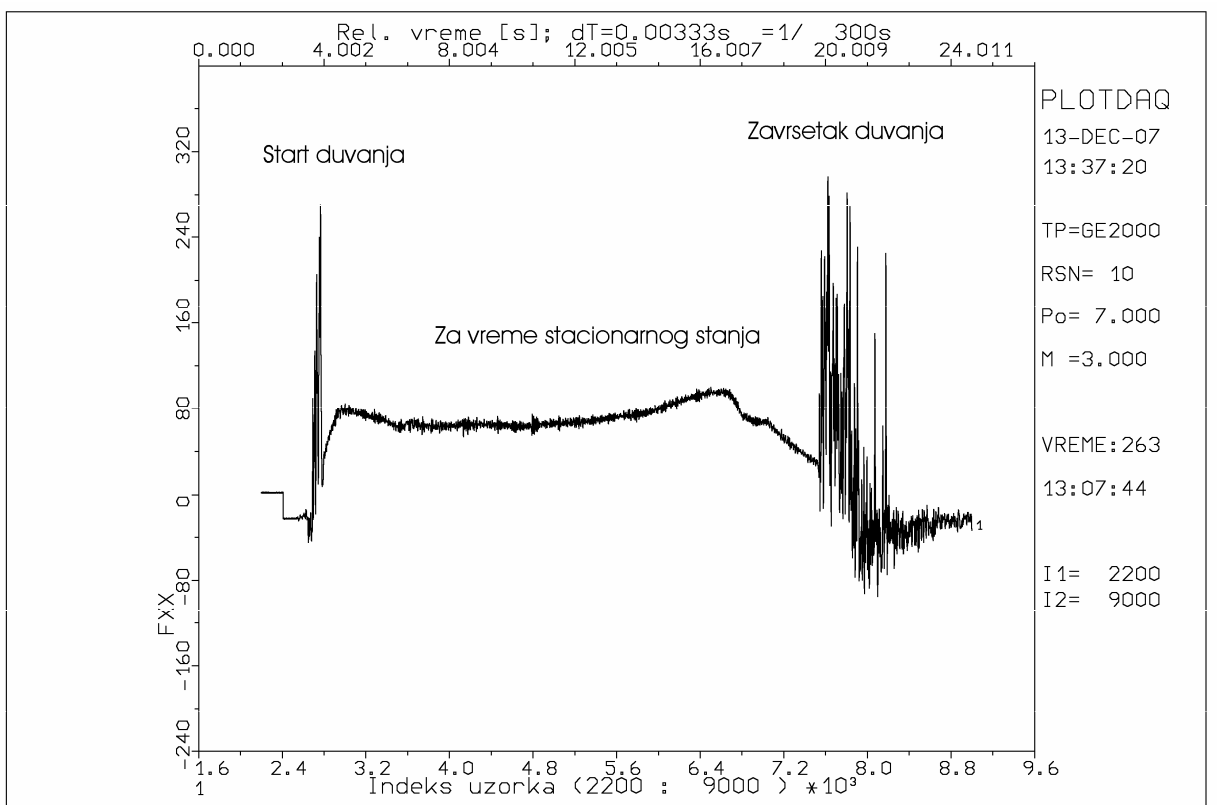

SI. 6 - Sila otpora (FXX) na Modelu 1 za vreme prelaznih i stacionarnih režima strujanja pri $\mathrm{M}=3,0$

SI. 7 - Moment skretanja (MZZ) na Modelu 1 za vreme prelaznih i stacionarnih režima strujanja pri $\mathrm{M}=3,0$

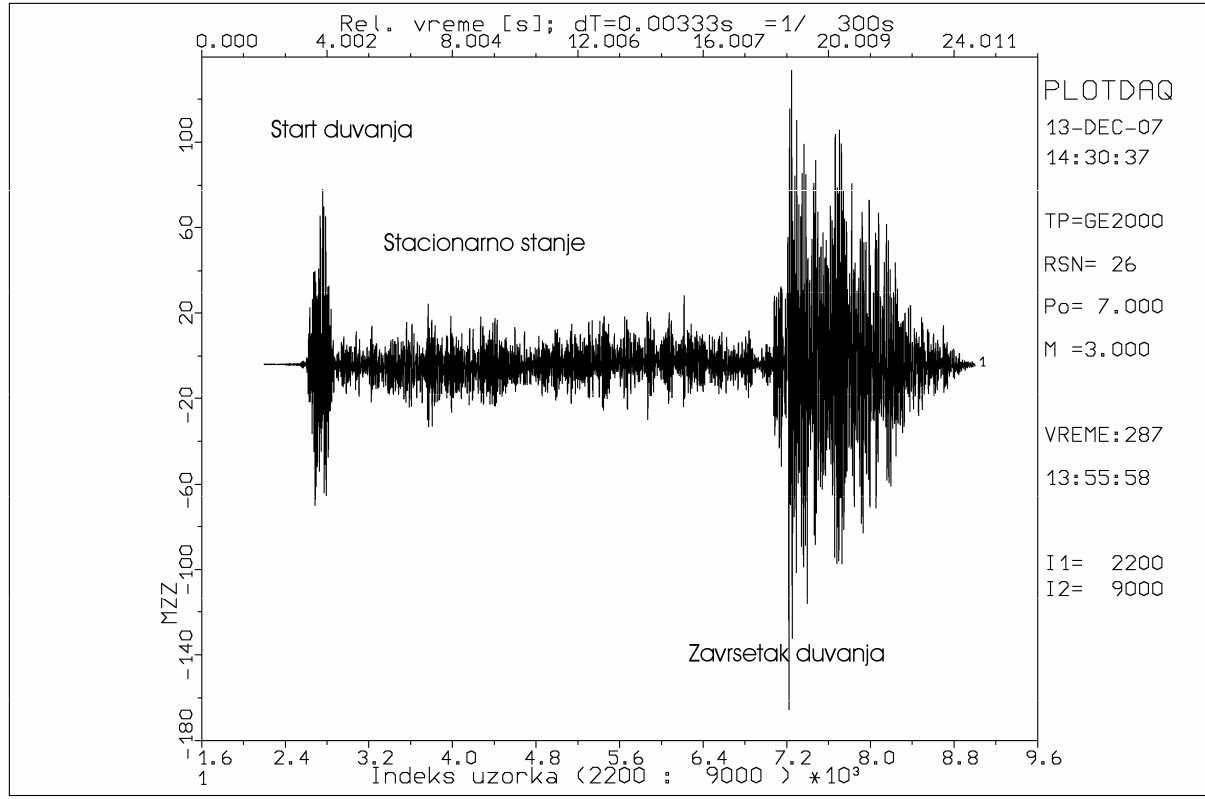


Tabela 1

Pregled sakupljenih podataka za merenje prelaznih opterećenja na Modelu 1

\begin{tabular}{|c|c|c|c|c|c|c|c|c|c|c|c|c|c|c|}
\hline $\begin{array}{c}\text { Redni } \\
\text { broj }\end{array}$ & $\mathrm{M}$ & $\begin{array}{c}\mathrm{P}_{0} \\
{[\mathrm{bar}]}\end{array}$ & $\begin{array}{c}\mathrm{FXX} \\
{[\mathrm{N}]}\end{array}$ & $\begin{array}{c}\mathrm{FYY} \\
{[\mathrm{N}]}\end{array}$ & $\begin{array}{c}\mathrm{FZZ} \\
{[\mathrm{N}]}\end{array}$ & $\begin{array}{c}\mathrm{MXX} \\
{[\mathrm{Nm}]}\end{array}$ & $\begin{array}{c}\mathrm{MYY} \\
{[\mathrm{Nm}]}\end{array}$ & $\begin{array}{c}\mathrm{MZZ} \\
{[\mathrm{Nm}]}\end{array}$ & $\mathrm{k}_{\mathrm{x}}$ & $\mathrm{k}_{\mathrm{y}}$ & $\mathrm{k}_{\mathrm{z}}$ & $\mathrm{k}_{\mathrm{l}}$ & $\mathrm{k}_{\mathrm{m}}$ & $\mathrm{k}_{\mathrm{n}}$ \\
\hline 8 & 2,5 & 4,0 & 320 & 1000 & 650 & 8 & 120 & 140 & 9,65 & 2,16 & 1,4 & 1,2 & 3,7 & 4,3 \\
\hline 10 & 3,0 & 7,0 & 315 & 1200 & 1800 & 10 & 200 & 170 & 9,57 & 2,59 & 3,88 & 1,6 & 6,2 & 5,2 \\
\hline 15 & 2,5 & 4,0 & 360 & 1200 & 1350 & 10 & 150 & 200 & 10,9 & 2,59 & 2,91 & 1,6 & 4,6 & 6,2 \\
\hline 16 & 3,0 & 7,0 & 365 & 1200 & 2400 & 10 & 200 & 200 & 11,0 & 2,59 & 5,17 & 1,6 & 6,2 & 62 \\
\hline 25 & 2,5 & 4,0 & 380 & 1650 & 800 & 18 & 140 & 120 & 11,5 & 3,56 & 1,73 & 2,8 & 4,3 & 3,7 \\
\hline 26 & 3,0 & 7,0 & 470 & 1650 & 1600 & 16 & 180 & 170 & 14,2 & 3,56 & 3,45 & 2,5 & 6,2 & 3,2 \\
\hline 28 & 2,5 & 4,0 & 360 & 1350 & 1000 & 12 & 160 & 140 & 10,9 & 2,90 & 2,20 & 1,9 & 4,9 & 4,3 \\
\hline 27 & 3,0 & 7,0 & 400 & 1200 & 1300 & 10 & 200 & 200 & 12,1 & 2,59 & 2,80 & 1,6 & 6,2 & 6,2 \\
\hline 40 & 2,5 & 4,0 & 370 & 1100 & 1600 & 16 & 120 & 140 & 11,2 & 2,37 & 3,45 & 2,5 & 3,7 & 4,3 \\
\hline 41 & 3,0 & 7,0 & 360 & 1700 & 1600 & 12 & 160 & 200 & 10,9 & 3,66 & 3,45 & 1,9 & 4,9 & 6,2 \\
\hline 48 & 2,5 & 4,0 & 420 & 1200 & 1400 & 10 & 120 & 200 & 12,7 & 2,59 & 3,02 & 1,6 & 3,7 & 6,2 \\
\hline 47 & 3,0 & 7,0 & 320 & 1700 & 2000 & 12 & 160 & 200 & 9,65 & 3,66 & 4,30 & 1,9 & 4,9 & 6,2 \\
\hline 56 & 2,5 & 4,0 & 380 & 1500 & 1200 & 12 & 140 & 120 & 11,5 & 3,23 & 2,59 & 1,9 & 4,3 & 3,7 \\
\hline 57 & 3,0 & 7,0 & 320 & 1600 & 2400 & 12 & 200 & 170 & 9,65 & 3,45 & 5,17 & 1,9 & 6,2 & 5,2 \\
\hline
\end{tabular}

Tabela 2

Pregled sakupljenih podataka za merenje prelaznih opterećenja na Modelu 2

\begin{tabular}{|c|c|c|c|c|c|c|c|c|c|c|c|c|}
\hline $\begin{array}{c}\text { Red. } \\
\text { broj }\end{array}$ & $\mathrm{M}$ & $\begin{array}{c}\mathrm{P}_{0} \\
{[\text { bar] }}\end{array}$ & $\begin{array}{c}\mathrm{FXX} \\
{[\mathrm{N}]}\end{array}$ & $\begin{array}{c}\mathrm{FYY} \\
{[\mathrm{N}]}\end{array}$ & $\begin{array}{c}\mathrm{FZZ} \\
{[\mathrm{N}]}\end{array}$ & $\begin{array}{c}\mathrm{MYY} \\
{[\mathrm{Nm}]}\end{array}$ & $\begin{array}{c}\mathrm{MZZ} \\
{[\mathrm{Nm}]}\end{array}$ & $\mathrm{k}_{\mathrm{x}}$ & $\mathrm{k}_{\mathrm{y}}$ & $\mathrm{k}_{\mathrm{z}}$ & $\mathrm{k}_{\mathrm{m}}$ & $\mathrm{k}_{\mathrm{n}}$ \\
\hline 5 & 2,0 & 2,3 & 54 & 148 & 102 & 2,8 & 4,6 & 4,34 & 2,3 & 1,63 & 2,17 & 3,6 \\
\hline 8 & 2,5 & 4,0 & 100 & 204 & 290 & 9,571 & 6,37 & 8,04 & 3,27 & 4,64 & 7,41 & 4,93 \\
\hline 9 & 3,0 & 6,0 & 71 & 184 & 240 & 14,13 & 5,3 & 5,71 & 2,9 & 3,8 & 10,9 & 4,01 \\
\hline 17 & 2,0 & 2,3 & 56 & 51 & 48 & 1,6 & 1,63 & 4,5 & 0,82 & 0,77 & 1,24 & 1,26 \\
\hline 18 & 2,5 & 4,0 & 96 & 260 & 200 & 8,72 & 7,54 & 7,72 & 4,16 & 3,2 & 6,75 & 5,86 \\
\hline 19 & 3,0 & 6,0 & 133 & 185 & 250 & 13,4 & 5,67 & 10,69 & 2,96 & 4,01 & 10,4 & 4,39 \\
\hline
\end{tabular}

\section{Analiza snimaka efekata vizualizacije strujanja}

Prikazano je nekoliko snimaka Modela 2 snimljenih metodom Šliren za vreme ispitivanja $u$ aerotunelu T-38. Na slici 8 prikazan je snimak uzet za vreme strujanja u stacionarnom režimu strujanja kada je već bio uspostavljen Mahov broj $M=3$. U pitanju je Model 2 koji se u tom trenutku nalazio pri napadnom uglu od 0 stepeni. Na snimku se jasno vidi kosi udarni talas formiran i vezan za vrh modela. Izvan polja ovog talasa strujanje je uniformno bez ikakvog poremećaja.

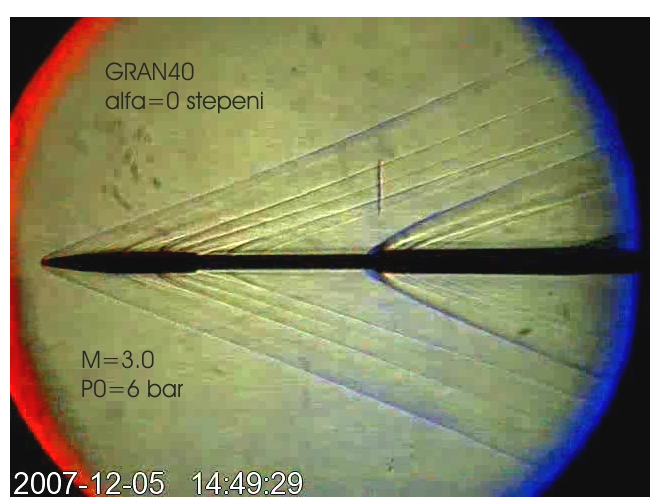

SI. 8 - Model 2 za vreme stacionarnog režima 


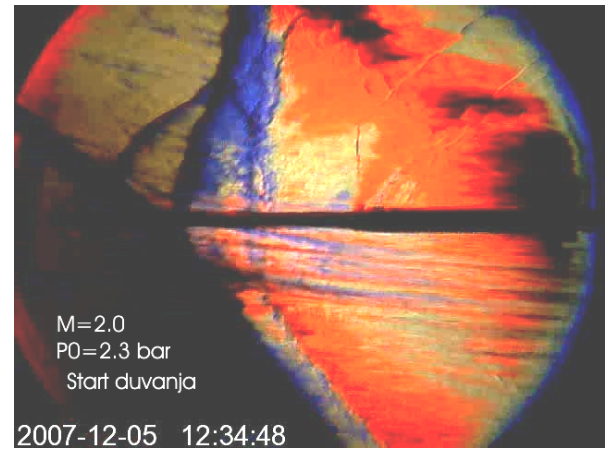

Sl. 9 - Model 2 za vreme prelaznog režima strujanja $\mathrm{M}=2$
Na slici 9 prikazan je snimak iz rane faze formiranja strujanja u radnom delu aerotunela T-38 na Mahovom broju $M=2$. Na snimku se uočava nadolazeći normalni udarni talas pod uglom koji zahvata model i unosi razliku u pritiscima na gornjaci i donjaci modela. Svuda oko modela strujanje je jako turbulentno.

Slika 10 i slika 11 takođe prikazuju Model 2 u ranoj fazi uspostavljanja strujanja, ali ovog puta pri Mahovim brojevima $M=2,5$ i $M=3$. Na slikama se još jasnije uočavaju normalni udarni talasi koji nose diskontinuitet u pritiscima i koji zbog toga pomeraju model na jednu, odnosno drugu stranu.

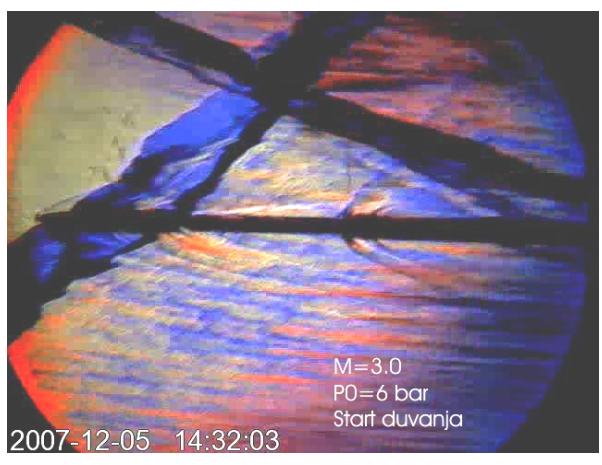

SI. 10 - Model 2 za vreme prelaznog režima strujanja pri $\mathrm{M}=2,5$

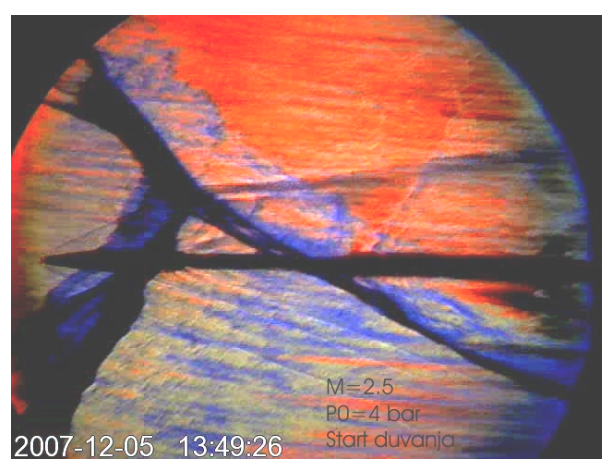

Sl. 11 - Model 2 za vreme prelaznog režima strujanja pri $\mathrm{M}=3,0$

\section{Rezultati ispitivanja}

Rezultati ispitivanja prikazani su na dijagramu na slici 12. Punom linijom su prikazani rezultati iz ranijih ispitivanja prelaznih opterećenja, a kvadratićima i kružićima rezultati dobijeni ispitivanjem Modela 1 i Modela 2.

Za koeficijente normalizovane sile otpora može se reći da su, za oba modela i sve Mahove brojeve, u području očekivanih vrednosti. Isto važi i za normalizovane koeficijente momenta skretanja.

Izmereni normalizovani koeficijenti bočne sile i momenta propinjanja se, sa izuzetkom nekoliko tačaka, nalaze, takođe, u području gde se i očekuju.

Jedna polovina koeficijenata normalne sile nalazi se izvan očekivanog područja, dok je druga polovina unutar njega. Za naredne modele 
koji se budu ispitivali pri supersoničnim brzinama izvan 2 Maha ovi dobijeni podaci se moraju ozbiljno uzeti u obzir.

Normalizovan koeficijent momenta valjanja za Model 2 bio je nula, jer taj model nije imao krila. Dobijeni rezultati za Model 1 pokazuju da su veći od očekivanih, što se može objasniti činjenicom da su kod ovog modela krila, olučasta ili pravougaona, bila dosta velika.
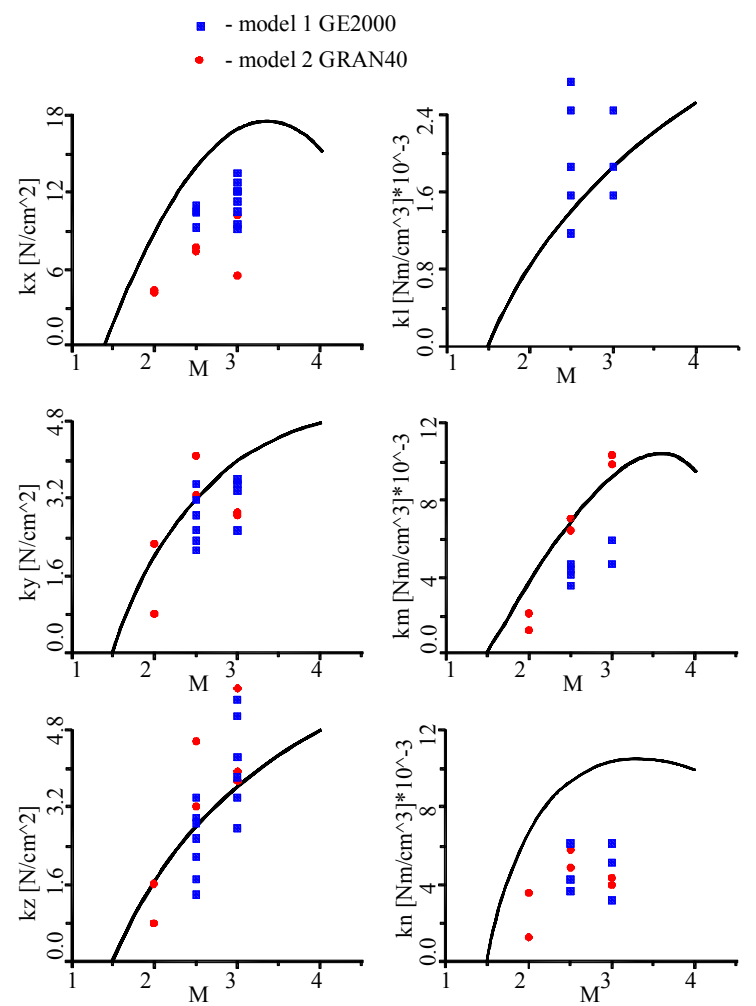

SI. 12 - Rezultati ispitivanja Modela 1 i Modela 2 u aerotunelu T-38

\section{Zaključak}

Kao i ranija ispitivanja prelaznih opterećenja i ova su dala vrlo korisne kvalitativne $\mathrm{i}$ kvantitativne podatke u razjašnjavanju pojava koje se javljaju pri startu i zaustavljanju rada aerotunela na Mahovim brojevima preko 2. U pripremnoj fazi, pri izboru aerovage i veličine modela koji treba da bude ispitan na velikim supersoničnim brzinama, dobijeni podaci se moraju vrlo ozbiljno uzeti u obzir. 


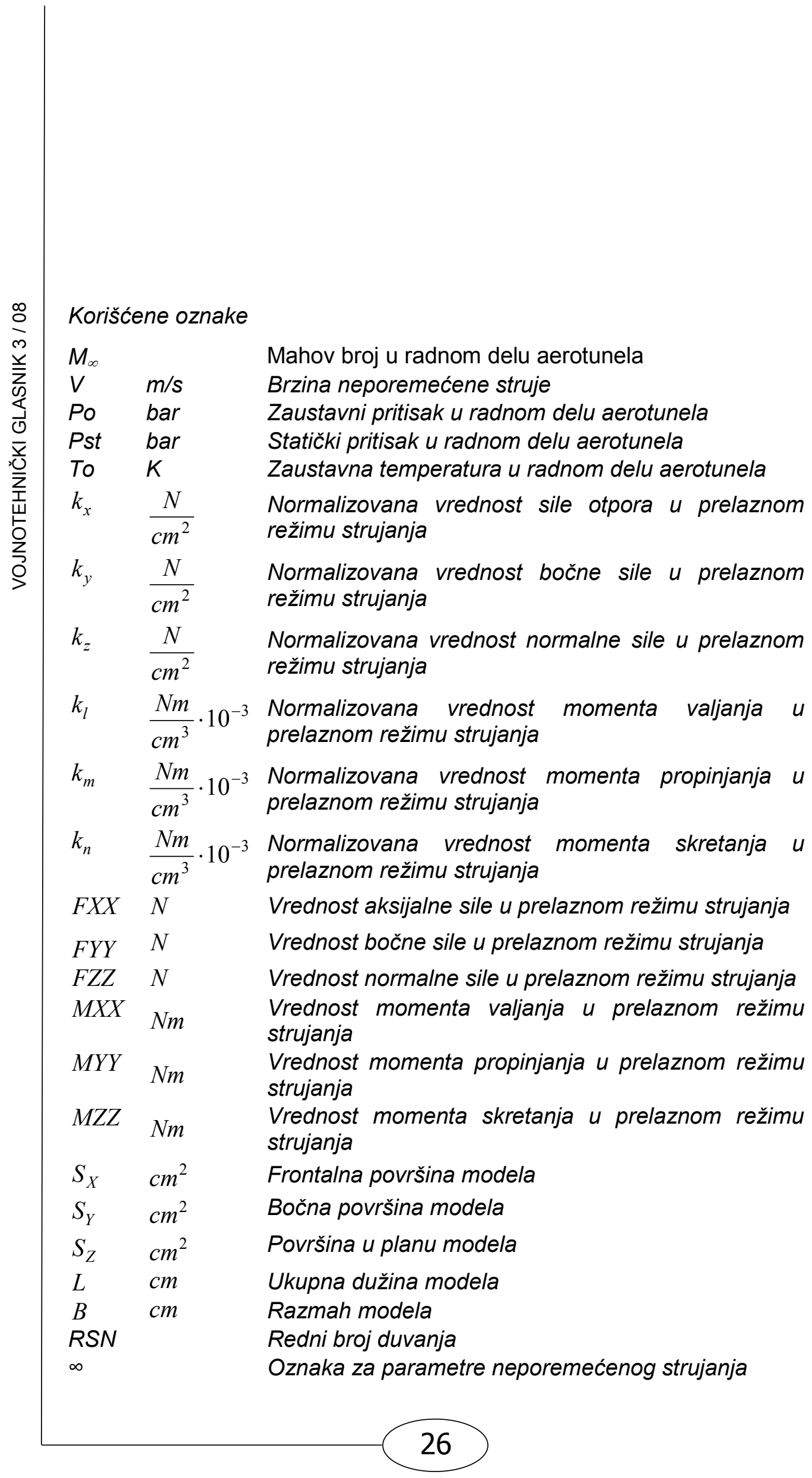




\section{Literatura}

0,5 do 3,0 Maha u aerotunelu T-38 VTI, interni izveštaj V3-2873-I, Vojnotehnički institut, Beograd.

[6] Samardžić, M.: Ispitivanje granate prečnika $40 \mathrm{~mm}$ u aerotunelu T-38 VTI, interni izveštaj V3-2982-I, Vojnotehnički institut, Beograd.

[7] Elfstrom, G.M., Medved, B.: The Yugoslav 1,5 m Trisonic Blowdown Wind Tunnel, AIAA Paper 86-0746-CP.

[8] Vuković, Đ., Vitić A.: Modernizacija Šliren sistema u aerotunelu T-38 VTI, interni izveštaj V3-2981-A, Vojnotehnički institut, Beograd. 